\title{
The Amount of Straw for Growing-Finishing Pigs Considering the Reduction of Time Spent in Manipulative Behavior
}

\author{
L. Bodin ${ }^{1,2}$, B. Algers ${ }^{1 *}$, M. Andersson ${ }^{2}$, AC. Olsson ${ }^{2}$ and J. Botermans ${ }^{2}$ \\ ${ }^{1}$ Department of Animal Environment and Health, Swedish University of Agricultural Sciences, P.O. Box 234, 53223 SKARA, Sweden \\ ${ }^{2}$ Department of Biosystems and Technology, Swedish University of Agricultural Sciences, Sundsvägen, 123053 ALNARP, Sweden
}

Received: September 30, 2014; Accepted: July 03, 2015; Published: July 09, 2015

*Corresponding author: B. Algers, Department of Animal Environment and Health, Swedish University of Agricultural Science, P.O. Box 234, 532 23 SKARA, Sweden, Tel: +0046-51167000; E-mail: bo.algers@slu.se

\begin{abstract}
The behavior of rooting and digging is highly motivated in the pig. The motivation to perform this exploratory behavior is not reduced even after the dietary requirement has been fulfilled through feeding. The aim of this study was to identify the minimal amounts of straw needed to satisfy pig motivation for manipulation and reduce to a minimum the manipulating behavior of pigs directed toward pen mates. To determine the minimal amount of straw needed for conventional growing-finishing pigs, a study using 168 pigs provided with 7 different amounts of straw $(20,40,60,80,100$, 200 or 300 grams/ pig/ day) was performed. The straw was provided either once or four times per day. Behavior observations were made using focal animal sampling and continuous recording for one hour between 9 and 10 am and between 3 and $4 \mathrm{pm}$.

The time spent by the pigs manipulating straw increased over $10 \%$ ranging up to $27 \%$ in all the pens receiving over $200 \mathrm{~g}$ of straw per day compared to the range from $4-22 \%$ in pens receiving $20-100 \mathrm{~g}$ of straw. Meanwhile, the time spent in redirected behavior decreased below $5 \%$ in all the pens receiving over $200 \mathrm{~g}$ of straw per day. No significant differences were found when comparing pens provided with straw once or four times per day.
\end{abstract}

Keywords: Growing-finishing pigs; Straw; Redirected behavior; Manipulation

\section{Introduction}

In the pigs natural environment the animals spend a large part of the day exploring their surroundings and searching for food $[1,2]$. The rooting and digging behaviors in the ground are highly motivated in the pigs. Pigs are active in the morning and afternoon and the motivation to perform exploratory behavior is not decreased even after the dietary requirement has been fulfilled through feeding [2]. If this behavior cannot be performed, the pig may instead begin to perform abnormal behavior as a substitute to the exploratory behavior. These, such as tail biting, are not wanted because they may damage the skin of the pigs, for example, which in turn has implications for their welfare [2-4].

The provision of straw is a well-studied means of reducing redirected behavior towards pen mates as concluded in a review by Studnitz et al. [2]. The provision of straw appears to be more successful in reducing redirected behavior than supplying more space $[2,5]$. Straw also has the capacity to keep pigs interested even in the long-term [6-8]. Studies show that when more straw is provided, the more exploratory behavior is directed towards the straw and not to the pen mates [9]. Amounts of up to $2 \mathrm{~kg}$ straw per day show a proportional increase in exploratory behavior directed towards the material and decrease in redirected behavior $[2,10]$.

The EU Commission Directive (2001/93/EC) states that: "pigs must have permanent access to sufficient quantity of material to enable proper investigation and manipulation activities, such as straw, hay, wood, sawdust, mushroom compost, peat or a mixture of such, which does not compromise the health of the animals".

In the Swedish animal welfare legislation (Jordbruksverket) [11] the provision of straw is mentioned in chapter $3,7 \S$ as:"... bedding product shall be given in such quantities so that they meet the pigs' needs for exploration and comfort....".

The EU directive is made to meet the exploratory needs of the pigs and reduce abnormal behaviors directed towards pen mates, thus improving welfare. However, when straw is provided it may clog the slats and drainage so that the removal of feces is hampered unless appropriate slat and slot widths and straw dimensions are used [12]. The management of straw increases the work for the animal keeper and involves extra costs.

Neither the Commission Directive nor the Swedish animal welfare regulation mentions the amount of straw that ought to be provided. Furthermore, the minimum amount of straw needed to satisfy the pigs motivation and the minimum amount of straw that reduce abnormal behavior directed towards pen mates needs further investigation. Therefore, the aim of this study was to identify the minimal amounts of straw needed to satisfy pig motivation for manipulation and reduce to a minimum the manipulating behavior of pigs directed toward pen mates. 
The hypothesis is that the more straw that is provided, the more manipulative behavior towards straw will be performed and less redirected behaviors will be performed. Furthermore, provision of straw several times per day will result in more manipulative behavior directed towards straw and less behavior directed towards pen mates.

\section{Material and methods}

\section{Animals and housing}

The pigs in this study were kept at the research farm of the Swedish University of Agricultural Sciences in Scania country in southern Sweden, in conventional insulated buildings, using pens with slatted floor in the dunging area. The pigs had a lying area of $0.64 \mathrm{~m}^{2}$ per pig, a dunging area of $0.39 \mathrm{~m}^{2}$ per pig and a feed trough length of $0.33 \mathrm{~m}^{2}$ per pig. The pens were smaller than conventional allowing for more detailed observations. A total of 168 growing-finishing pigs divided in three batches with 14 groups of 4 in each batch were used. All pigs [(LRxY)xH breed] were housed in the same place, cared by the same keeper and provided with a standard feed ration (Simonsson [13] and the same type of straw chopped to lengths ranging from $0.01 \mathrm{~m}$ to 0.1 $\mathrm{m}$ to fit the manure handling system. The introduction of the pigs from the first batch was done in December, the second in April and the third in August 2011. All pigs had previous experience with a daily allowance of a handful of straw. The average temperature inside the pig house was $15.8^{\circ} \mathrm{C}, 19.4^{\circ} \mathrm{C}$ and $23.0^{\circ} \mathrm{C}$ in batches 1, 2 and 3 respectively. The groups were subject to different treatments including:

- 7 different amounts of straw $(20,40,60,80,100,200$ or 300grams/ pig/ day)

- Straw rationed once daily (10 am) or divided in four equal batches times per day (10 am, 12pm, 2pm and $4 \mathrm{pm})$.

The straw daily provisions were each weighed separately. Those groups that received straw four times per day were placed with a wall separating them from the groups which only received straw once daily, to minimize the effect of one group to the other.

\section{Behavior observations}

Preparations in the pig house: Seven weeks after housing, the pigs were video recorded using the MSH-Video, 2010. [14] Four groups of pigs were recorded simultaneously during 24 hours (2 groups provided with straw once/day and 2 groups provided with straw 4 times /day).

Feeding took place at $8.30 \mathrm{am}$ and at $2.30 \mathrm{pm}$. The behavior was observed in detail by one observer throughout the study using focal animals sampling and continuous recording for one hour between 9 and 10 am and between 3 and 4 pm. At the time of observation, the observer did not receive any information about which treatment each pen was subjected to. The observations were done after feeding with the assumption that the pigs would have a strong motivation to perform manipulative behavior after feeding [2].

Observations: The behaviors observed are presented in the ethogram in table 1 . The observations began following the first focal animal and every time the animal changed its behavior a note was made in an Excel file. All four pigs in the pen served as focal animal during 15 minutes of each hour of observation.

When a starting time had been decided a focal animal was chosen at random. The order in which the other pigs in the pen should be observed was then randomly picked.

In the current study one "bout" is the time spent in one behavior without any interruptions of other behaviors from the ethogram except "walking" or "resting".

If a clear distinction of a behavior could not be determined then the behavior was noted as missing value.

Data processing: The total time spent in each behavior was calculated. The behavior "riding" was removed because no incidence of that behavior was recorded during the periods of observation. The behaviors "nibbling", "tail bite" and "ear bite" were combined into "redirected behavior" which is the term used in the following.

The statistical analysis was made using multiple linear regressions in SAS (SAS Inst. Inc., Cary, NC, USA), [15] and descriptive analyses were done using the broken stick model and charts with trend lines in Microsoft Office: Excel $2007^{\circledR}$.

The broken stick model was considered because of its possibility to point at a value on the minimal amount of straw to growing-finishing pigs. This value represents the point where an increase in the provision of straw no longer affects the behavior further. The data was run through the program Mat Lab (Math works Inc.) [16] which created a chart with a trend line. Optimally, the trend line should increase/decrease in the beginning to then

\begin{tabular}{|c|c|}
\hline Behavior variables & Definition \\
\hline Resting & $\begin{array}{l}\text { Lying, standing, sitting without performing other } \\
\text { behaviour }\end{array}$ \\
\hline Walking & Taking steps without performing other behaviour \\
\hline Eating & Nose in feed trough \\
\hline Drinking & Manipulating water nipple \\
\hline Manipulating straw & Nibbling/ rooting/ biting on floor \\
\hline $\begin{array}{l}\text { Manipulating envi- } \\
\text { ronment }\end{array}$ & $\begin{array}{l}\text { Nibbling/ rooting/ biting on surface above ground } \\
\text { level }\end{array}$ \\
\hline Fence contact & $\begin{array}{l}\text { Interaction/ sniffing/ biting/ pawing one or more } \\
\text { pigs in adjacent pen }\end{array}$ \\
\hline Aggression & $\begin{array}{l}\text { Two or more pigs in the same pen are fighting by } \\
\text { oral contact }\end{array}$ \\
\hline Riding & A pig is mounting another pig \\
\hline Nibbling & A pig nibbles another pig \\
\hline \multirow{2}{*}{ Belly massage } & A pig is massaging another pig's belly/ side \\
\hline & with a visible vertical movement \\
\hline Tail biting & A pig is biting/ touching/ sucking another pig's tail \\
\hline Ear biting & A pig is biting/ touching/ sucking another pig's ear \\
\hline Other & Behaviour not included in ethogram \\
\hline
\end{tabular}


slope out at a breaking point (c-value). Mat Lab is programmed to find the best possible breaking point within the range of the data.

\section{Results}

\section{Behavioral observations}

No significant differences were found between pens provided with straw once or four times per day concerning the behaviors manipulating straw and redirected behavior (Tables 2 and 3 ). Results of manipulating straw and redirected behavior are presented separately as they are signs of different motivational systems governing pig behavior.

\section{Manipulating straw}

Broken stick: The chart with the manipulating straw behavior showed an inverted line with a c-value at $100 \mathrm{~g}$ of straw and a maximum at $300 \mathrm{~g}$ (figure 1(a)). An inverted line suggests that the breaking point is located somewhere outside the range of the study.

Polynomial trend line: The polynomial trend line of the

\begin{tabular}{|l|l|l|}
\hline Table 2: Prevalence of behaviour \%. \\
\hline Behaviour & $\begin{array}{l}\text { One time straw per } \\
\text { day }\end{array}$ & $\begin{array}{l}\text { Four times straw } \\
\text { per day }\end{array}$ \\
\hline Walking & 2.9 & 3.5 \\
\hline Resting & 56.7 & 56.8 \\
\hline Eating & 17.3 & 15.9 \\
\hline Drinking & 2.5 & 2.1 \\
\hline Manipulating straw & 13.6 & 13.1 \\
\hline $\begin{array}{l}\text { Manipulating } \\
\text { environment }\end{array}$ & 2.9 & 2.4 \\
\hline $\begin{array}{l}\text { Fence contact } \\
\text { neighbouring pigs }\end{array}$ & 0.9 & 0.7 \\
\hline Aggression & 0.1 & 0.1 \\
\hline Redirected behaviour & 2.4 & 3.2 \\
\hline Belly massage & 0.4 & 1.9 \\
\hline Other & 0.3 & 0.3 \\
\hline
\end{tabular}

Table 3: R-square values of the statistical models.

\begin{tabular}{|c|c|c|c|}
\hline Statistical Model & $\begin{array}{l}\text { One time } \\
\text { straw per } \\
\text { day }\end{array}$ & $\begin{array}{l}\text { Four times } \\
\text { straw per day }\end{array}$ & $\begin{array}{l}\text { Combined data } \\
\text { (1and4 times straw } \\
\text { per day) }\end{array}$ \\
\hline \multicolumn{4}{|c|}{$\begin{array}{l}\text { Manipulating } \\
\text { straw (\% of time) }\end{array}$} \\
\hline $\begin{array}{l}\text { Polynomial trend } \\
\text { line }\end{array}$ & 0.28 & 0.26 & 0.26 \\
\hline $\begin{array}{l}\text { Logarithmic trend } \\
\text { line }\end{array}$ & 0.22 & 0.12 & 0.17 \\
\hline \multicolumn{4}{|l|}{$\begin{array}{l}\text { Redirected } \\
\text { behaviour }(\% \text { of } \\
\text { time) }\end{array}$} \\
\hline $\begin{array}{l}\text { Polynomial trend } \\
\text { line }\end{array}$ & 0.02 & 0.11 & 0.05 \\
\hline $\begin{array}{l}\text { Logarithmic trend } \\
\text { line }\end{array}$ & 0.01 & 0.11 & 0.04 \\
\hline
\end{tabular}

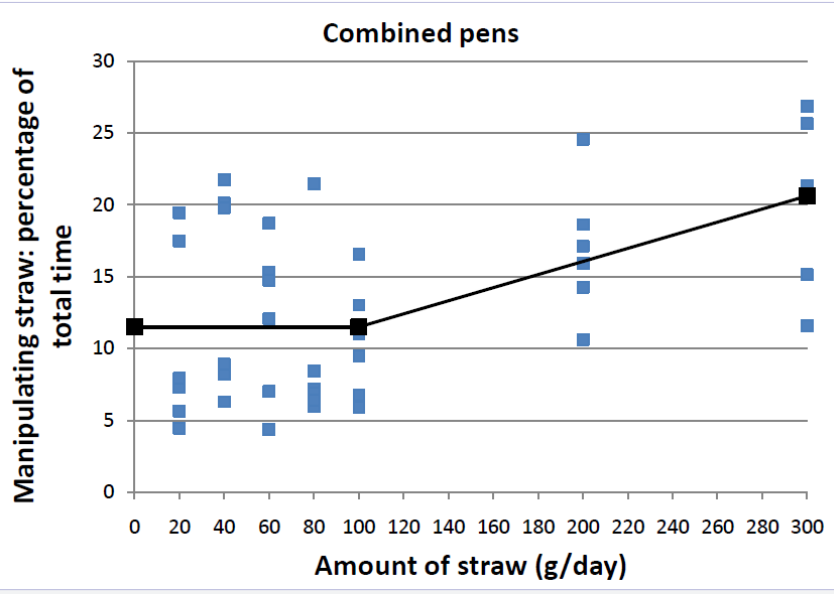

Figure 1a: Broken stick model showing manipulating straw from combined data of pens which received straw once or four times per day.

behavior "manipulate straw" continues to increase until it reaches a maximum at $300 \mathrm{~g}$ possibly rising even further if higher amounts of straw would have been tested in this study (figure1(b)).

Logarithmic trend line: The logarithmic trend line shows that the time spent manipulating straw is increased with increased provision of straw. A difference can be seen when observing the time spent in manipulative behavior in pens given straw $300 \mathrm{~g}$ per day. For all those pens, manipulative behavior directed towards straw occurred more than $10 \%$ of the time. Data also seem to be less spread compared to the pens which received 20-100g of straw per day (figure 1 (c)). When combining data from all the pens, the behavior manipulate straw increased with increasing amounts of straw.

\section{Redirected behavior}

Broken stick model: The broken stick model of redirected behavior showed a line with a breaking point at $200 \mathrm{~g}$ of straw (figure 2(a)).

Polynomial trend line: The polynomial trend line of redirected behavior seems to level out somewhere between 100$200 \mathrm{~g}$ of straw but the minimum is closer to $300 \mathrm{~g}$ (figure 2(b)).

Logarithmic trend line: The logarithmic trend lines show that time spent in redirected behavior was reduced with increased provision of straw (figure 2(c)).

\section{Discussion}

\section{Method}

External validity: The pigs were housed at the research farm to allow the detailed behavioral observations where the pens were smaller than in conventional farms and only four pigs were kept in each pen. No significant differences between group sizes were found for behaviors such as activity or aggression according to (Schmolke et. al; Spicer, Aherne) $[17,18]$. The different batches were studied in different periods of the year which means that parameters like temperature and humidity differed between 


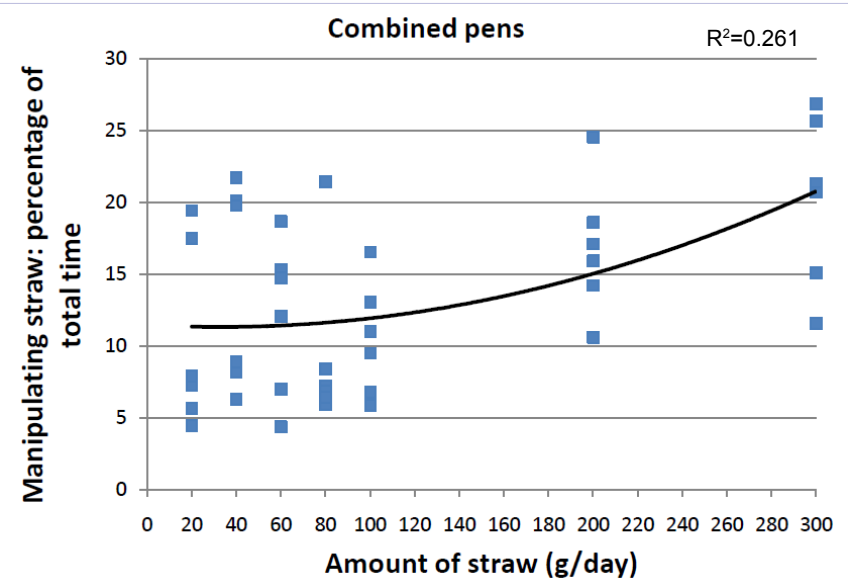

Figure 1b: Polynomial trend line showing manipulating straw from combined data of pens which received straw once or four times per day.

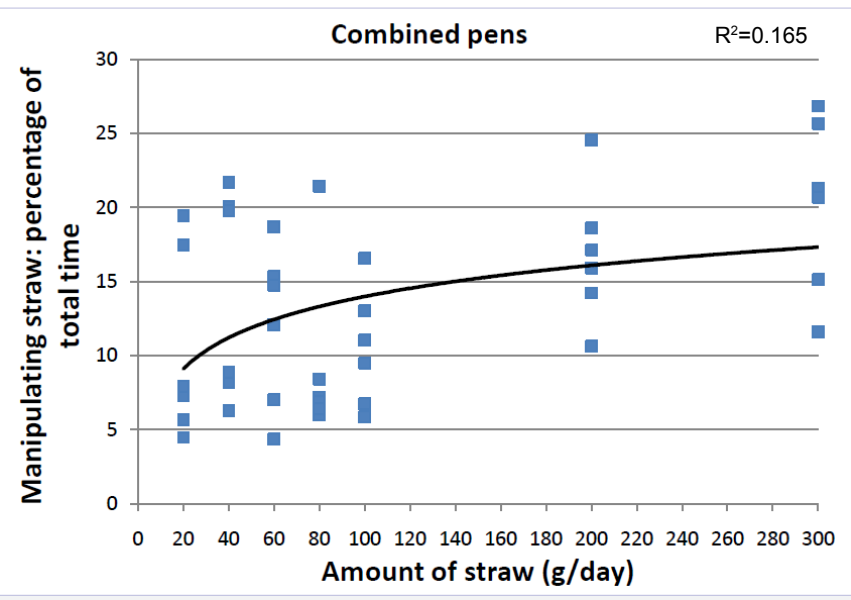

Figure 1c: Logarithmic trend line showing manipulating straw from combined data of pens which received straw once or four times per day.

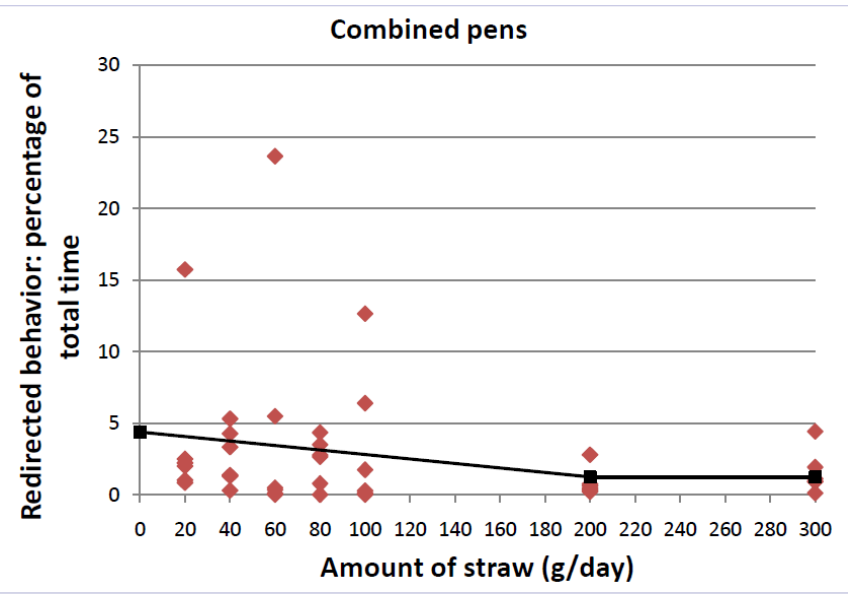

Figure 2a: Broken stick model showing redirected behavior from combined data of pens which received straw once or four times per day.

the batches. No significant differences in behavior were found between the batches however, suggesting that the results from the current study are valid independent of temperature at ranges between 15 and 23 degrees Celsius occurring in the present study.

\section{Observations}

Larger amounts of straw should have been used since the behavior "manipulate straw" seems to have its maximum beyond the limits of the current study.

The time for observations during the day were decided to take place as close to feeding as possible but still giving the pigs enough time to finish eating before the onset of the observations. During the first minutes of each observation the pigs were usually occupied in eating behavior which suggests that the time for observations and feeding should be further apart.

Analysis of data: The r-square values of the charts from the current study are very low (Table 3) indicating that the trend lines can only explain up to $30 \%$ of the variation in the data. The r-square values of the polynomial trend lines appear to be somewhat bigger than for the logarithmic trend lines. This suggests that the polynomial trend line describe the data better

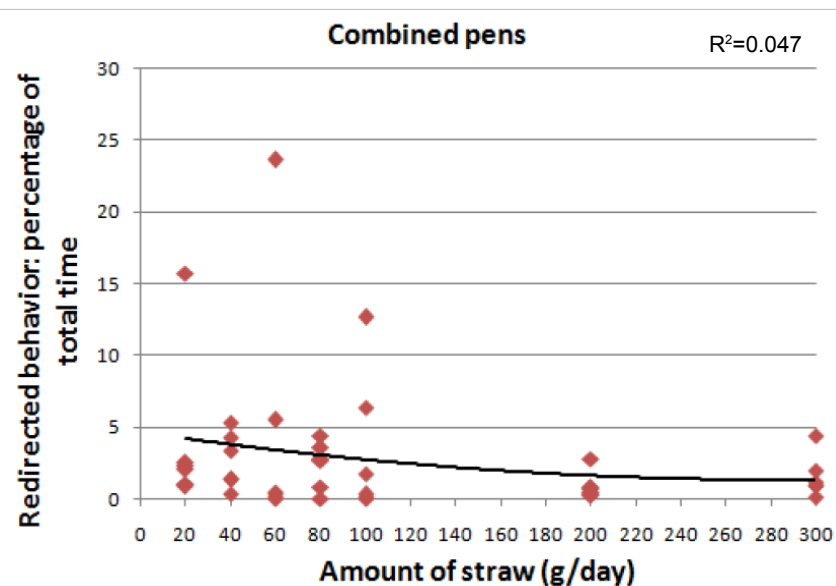

Figure 2b: Polynomial trend line showing redirected behavior from combined data of pens which received straw once or four times per day.

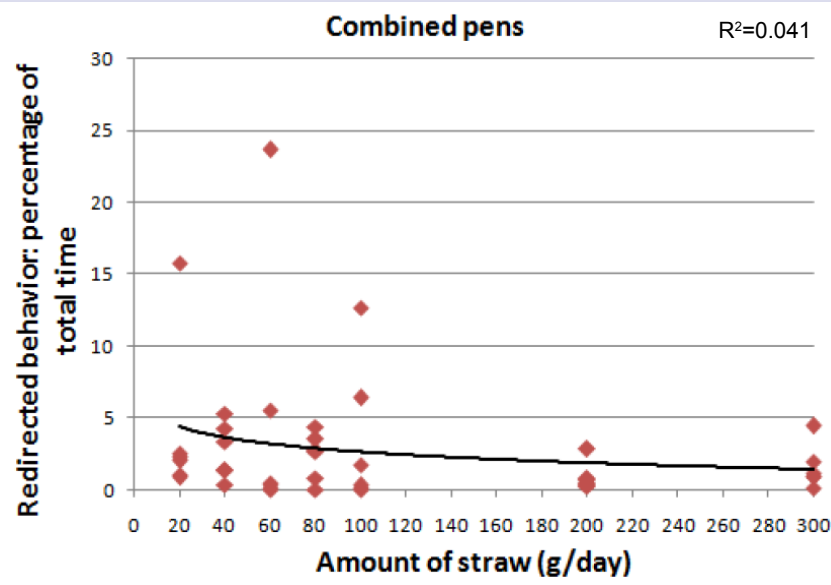

Figure 2c: Logarithmic trend line showing redirected behavior from combined data of pens which received straw once or four times per day. 
than the logarithmic.

\section{Behavior observations}

Manipulating straw: In modern pig production, where the opportunity for pigs to root and graze is minimized, the provision of straw is an important factor for the well-being of pigs. Straw provided to the pigs improve the possibility to perform elements of their natural behavior repertoire. The motivation to perform these behaviors is strong and if there is not substrate to manipulate, the pig will direct the manipulation elsewhere, for example towards pen mates [2-4]. So, the more time that is spent on manipulating straw the less time is spent in redirected behavior.

The broken stick model proved insufficient in producing a valid breaking point for the behavior "manipulating straw" inside the limits of this study. Several studies show that the provision of straw up to $2 \mathrm{~kg}$ per day [10] and above [6] results in a proportional increase in explorative behavior directed towards straw. This further suggests that the amount of straw needed for pigs to perform a maximum of manipulative behavior towards straw is beyond the $300 \mathrm{~g}$ which is the maximum amount observed in the current study.

Even if no maximum was found in the current study, a clear distinction was observed when comparing the pens receiving $20-100 \mathrm{~g}$ of straw and 200-300g of straw. The time spent in manipulative behavior directed towards straw was increased over $10 \%$ ranging up to $27 \%$ in all the pens receiving over $200 \mathrm{~g}$ of straw per day compared to the range from $4-22 \%$ in pens receiving 20-100g of straw. The data are also less varied from pens provided with over $200 \mathrm{~g}$ of straw which suggests that a larger proportion of the animals were affected more equally to the treatment. As opposed to increased feeding frequencies [19] no effects on manipulating or redirected behaviors were found in this study.

Redirected behavior: The hypothesis that the prevalence of redirected behavior should decrease with increasing amounts of straw is accepted. For the broken stick method, when the pens were combined regardless of the provisions, a breaking point at $200 \mathrm{~g}$ of straw was found after which no further improvements were seen. A clear distinction can be observed when comparing these pigs with the ones provided with $20-100 \mathrm{~g}$ of straw. The pigs from pens provided between $20-100 \mathrm{~g}$ of straw spent $0-24 \%$ of the time in redirected behavior. The variation in these pens was also large and for each amount of straw, at least one pen reached above $5 \%$. However, all the pigs from pens provided more than $100 \mathrm{~g}$ of straw spent less than $5 \%$ of the time in redirected behavior and the data from these pens were more cohesive.

Camerlink and Turner [20] studied the occurrence of nosing behavior directed towards pen mates and concluded that it often consists of a gentle nose-to-nose contact and nosing of the head and body. The authors define this behavior as social nosing and it is performed "for social recognition, as an affiliative behavior, to gain olfactory signals, or to satisfy an intrinsic need to nose". This social nosing should not be associated with injurious behaviors. For the current study the term redirected behavior is a combination of the behaviors "nibbling", "tail bite" and "ear bite" and there is a possibility that the behavior "nibbling" include these social nosing episodes. If social nosing had been separated from harmful nosing in the current study the results may have been different.

\section{Conclusions}

$300 \mathrm{~g}$ of straw, which is the highest amount of straw included in the currentstudy, is probably not enough for the pigs to perform manipulative behavior to maximum extent. The provision of at least $300 \mathrm{~g}$ of straw would increase time spent in manipulative behavior and thus to a better extent satisfy exploratory motivation. However, the minimum amount of straw needed to decrease time spent in redirected behavior to a minimum level seems to be around $200 \mathrm{~g}$ of straw. These results suggest that $200 \mathrm{~g}$ of straw per pig and day is the minimum amount necessary for pigs in conventional pig production in Sweden to be able to perform manipulative behavior and to decrease redirected behavior. The provision of the straw one or four times per day showed no difference in these results.

\section{Acknowledgements}

The project was funded by the Swedish Board of Agriculture and by Partnership Alnarp. We are grateful for statistical support from Jan-Eric England.

\section{References}

1. Stolba A, Wood-Gush DGM. The behavior of pigs in a semi-natural environment. Animal Production. 1989;48(2):419-425.

2. Studnitz M, Jensen MB, Pedersen LJ. Why do pigs root and in what will they root?: A review on the exploratory behavior of pigs in relation to environmental enrichment. Appl. Anim. Behav. Sci. 2007;107(3):183197.

3. EFSA. Scientific Opinion of the Panel on Animal Health and Welfare on a request from Commission. The risks associated with tail biting in pigs and possible means to reduce the need for tail docking considering the different housing and husbandry systems. The EFSA Journal. 2007;611:1-13.

4. Fraser D, Phillips PA, Thompson BK, Tennessen T. Effect of straw on the behavior of growing pigs. Appl. Anim. Behav. Sci. 1991;30(34):307-318.

5. Beattie VE, O'Connell NE. Relationship between rooting behaviour and foraging in growing pigs.Animal Welfare. 2002;11:295-303.

6. Day JEL, Burfoot A, Docking CM, Whittaker X, Spoolder HAM, Edwards SA. The effects of prior experience of straw and the level of straw provision on the behavior of growing pigs. Appl. Anim. Behav. Sci. 2002;76:189-202.

7. ZwickerB, Gygax L, Wechsler B, Weber R. Influence of the accessibility of straw in racks on exploratory behavior in finishing pigs. Livest. Sci. 2012;148(1-2):67-73.

8. ZwickerB, Gygax L, Wechsler B, Weber R. Short- and long-term effects of eight enrichment materials on the behavior of finishing pigs fed ad libitum or restrictively. Appl. Anim. Behav. Sci. 2013;144(1-2):31-38.

9. Munsterhjelm C, Peltoniemi OAT, Heinonen M, Ha“ ll O, Karhapa M, Valros A. Experience of moderate bedding affects behavior of growing pigs. Appl. Anim. Behav. Sci. 2009;118(1-2):42-53. 
10. Arey DS. Effect of straw on the behavior and performance of growing pigs in straw-flow pens. Farm Building Prog. 1993;112:24-25.

11. Jordbruksverket. Föreskrifter om djurskydd för lantbrukets djur. 07/06/2015. http://www.jordbruksverket.se/amnesomraden/djur/ djurhalsopersonal/veterinaraforfattningshandboken/ldjurskydd.4.6 beab0f111fb74e78a78000821.html.

12. Westin R, Holmgren N, Mattsson B, Algers B. Throughput capacity of large quantities of chopped straw in partly slatted farrowing pens for loose housed sows. Acta Agr. Scand. Sect. A Animal Science. 2013;63(1):18-27.

13. Simonsson A. Fodermedel och näringsrekommendationer för gris. Institutionen för husdjurens utfodring och vård, Swed. Univ. Agric. Sci. Report. 266. 2006.

14. MSH-Video, 07/06/2015. http://msh-video-client.software.informer. $\mathrm{com} /$.

15.SAS Institute Inc., http://www.sas.com/en_us/home.htmlhttp:// www.sas.com.
16. Math works Inc. 07/06/2015. http://www.mathworks.se/products/ statistics/index.html.

17. Schmolke SA, Li YZ, Gonyou HW.Effects of group size on social behavior following regrouping of growing-finishing pigs.Appl.Anim. Behav. Sci. 2004;88(1-2):27-38.

18. Spicer HM, Aherne FX. The Effects of Group Size/Stocking Density on Weanling Pig Performance and Behavior. Appl. Anim. Behav. Sci.1987;19(1-2):89-98.

19. Hessel EF, Wülbers-Mindermann M, Berg C, Van den Weghe HF, Algers B. Influence of increased feeding frequency on behavior and integument lesions in growing-finishing restricted-fed pigs. J Anim Sci. 2006;84(6):1526-1534.

20. Camerlink I, Turner SP. The pig's nose and its role in dominance relationships and harmful behaviour. Appl. Anim. Behav. Sci. 2013;145:84-91. 